\title{
Research on Center Village Location Based on AHP and GIS Spatial
}

\author{
Analysis \\ Yaoqi Yang ${ }^{1}$, Sucui $\mathrm{Li}^{2}$, Zheng Wang ${ }^{2}$, Yuanpei Yang ${ }^{1}$ \\ ${ }^{1}$ Peking University School of Economics, Beijing 100083, China \\ ${ }^{2}$ Land Reclamation and Ecological Reconstruction,China University of Mining and Technology \\ (Beijing), Beijing 100083,China
}

\begin{abstract}
Keywords:the planning of new countryside; the central village location; AHP; GIS spatial analysis;integrated analysis of multi-factors; cluster analysis

Abstract. The purpose of this paper is to solve the key problem of the planning of new countryside how to select the central village location. The research methods: The paper takes study town as the experimental subject, based on the second national land investigation. It determines each evaluating indicator's weight by the AHP law and builds the indicator system of land-potentiality evaluation. It gets each village's parameters through the GIS spatial analysis. Get the comprehensive scores of country-potentiality with integrated analysis of multi-factors.It chooses Cluster analysis to classify the result. Finally, it verifies the classification with the Voronoi theory and Central place theory. It is concluded that the central village location based on AHP and GIS is reasonable and it can provide evidence for the planning of new countryside.
\end{abstract}

\section{Introduction}

In order to enhance the practical application and operability of the research on center village construction, and further improve theory and methods of developing the center village construction, the paper will adopt a method which combine quantitative and qualitative, and establish the comprehensive evaluation model about potential of center village. And it also verifies and analyses the analysis results by using Thiessen Polygons Theory and Central Place Theory.

The study area is a large agricultural town in Henan Province, which has obvious exclusive district, scattered settlements, smaller scale (Figure 1). Datas of the study area will be from two tone results and statistical yearbooks. 


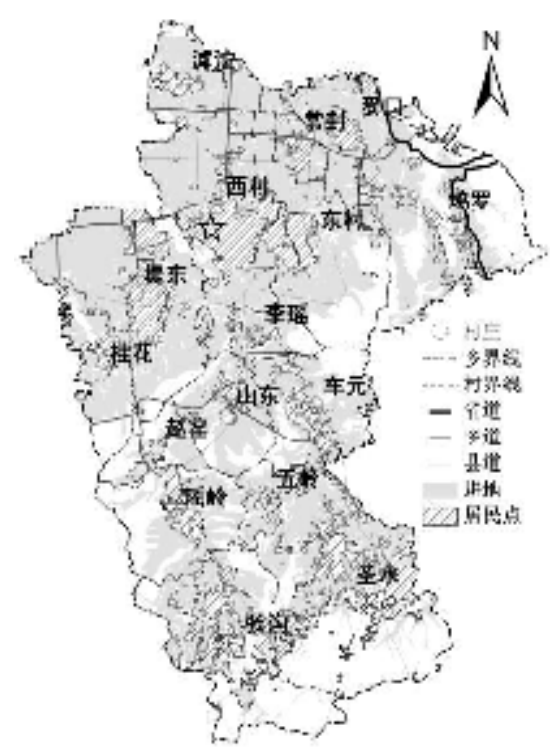

Fig.1 The distribution of Study Town

\section{Potential Evaluation Method of The Village Center And Data Processing}

\section{Construction of Evaluation Index System}

Because the factors affecting the development of the center village exist complex relationships, the paper use the Analytic Hierarchy Process (AHP) to determine the weight of each index, and calculates each factor weights by the YAAHP software. Then the results are as follows (Figure 2).

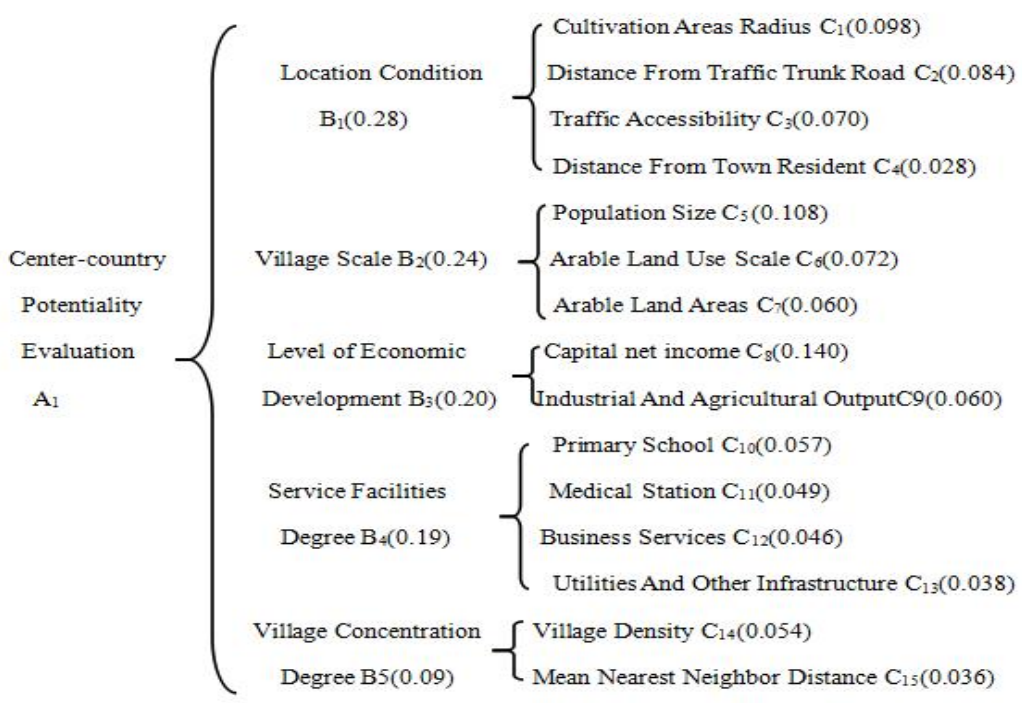

Fig.2 The indicator system of country-potentiality evaluation and the indicator's weight

Standardized Processing of Indicators

Part of the evaluation indicators can be obtained directly from the statistics, and the acquisition of other indicators need to adopt GIS spatial analysis in an indirect way, which include regional conditions and villages gather degrees.It should be standardized to unify the various units of measurement and indicators scores.There were positive correlation and negative correlation relationship between the evaluation indicators and villages potentiality, which were using respectively the formula (1) and (2) to conduct extreme treatment. 


$$
\begin{aligned}
& \left(X_{i}-X_{\min }\right) /\left(X_{\max }-X_{\min }\right) \times 100 \\
& \left(X_{\max }-X_{i}\right) /\left(X_{\max }-X_{\min }\right) \times 100
\end{aligned}
$$

$\mathrm{Xi}$----the indicators statistics, Xmax and Xmin ---express respectively maximum and minimum values of the index in this study area.The problem of farming radius should be effectively solved by Tyson Model, which aims at ensuring the shortest distance from the center village to the surrounding agricultural land.

What Thiessen Polygon Model for concrete is that: supposing the village set is $p-\left\{p_{1}, p, \ldots, p_{\mathrm{m}}\right\}$, and the number of villages are represented by $\mathrm{m}$, and $\mathrm{p}$ stands for free points for a rural region, and $\mathrm{d}(\mathrm{p}, \mathrm{pi})$ represents the distance between free point $\mathrm{p}(\mathrm{x}, \mathrm{y})$ and the village pi (xi , yi ). Then: $d\left(p, p_{i}\right)=\sqrt{\left(x-x_{i}\right)^{2}+\left(y-y_{i}\right)^{2}}$, and $d\left(p, p_{i}\right) \leq r . \mathrm{r}$ stands for farming radius, and that area $V_{n}=\left\{p \in E_{2}, d\left(x, p_{i}\right) \leq d\left(x, p_{j}\right), j=1,2, \ldots, m, j \neq i\right\}$ is the village Cultivation Areas. Thiessen polygons is generated according to the villages' location ( Figure 3 ). And their each boundary is the village's the cultivation areas. The farming radius and villages potential score are positively correlated, which means that the larger the farming radius, the greater cultivation areas, and the greater potentiality of the center country.

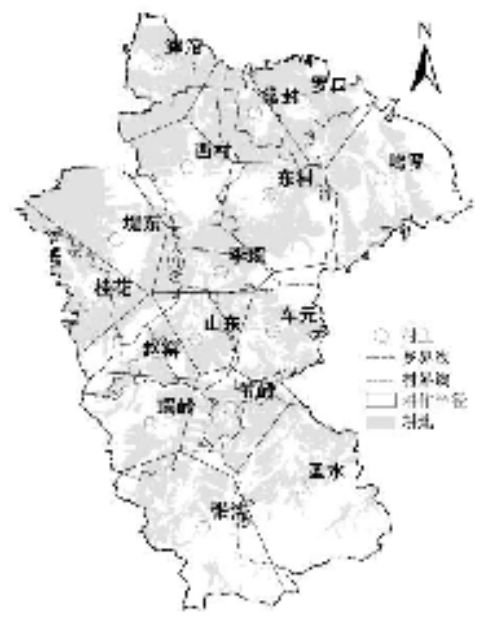

Fig.3 The Thiessen Polygon of the country

The distance of the traffic roads and the town resident can be got by using spatial approaching analysis to calculate the distance from the center point of country to the nearest traffic route or the center point of town.

The traffic accessibility can be got by calculating the total length of across village traffic lines, the longer the line,the better the traffic accessibility. The weight values is endowed according to the road level, and 1 is highway, and 0.5 is country road, and 0.2 is rural road.

Village concentration degree includes the village density and the mean nearest neighbor distance. Each village patch density and the mean nearest neighbor distance can be calculated by using the software of Fragstats. The greater patch density, the smaller the mean nearest neighbor distance, the more concentrated distribution of villages, the greater the potential for development. Patch density (PD) is defined as the number of rural settlements in per square kilometer patch, and it also reflects the intensity of rural settlements distribution. $P D=N / A$. N is the number of patches, A is the total area of landscape patches. Mean nearest neighbor distance (MNN) is mean distance from each rural 
settlement patch to its nearest neighbor body, and it also reflects relatively intensive nature of rural $M N N=\frac{1}{n} \cdot \sum_{i=1}^{n} h_{i}$.hi stands for the distance between i-th rural settlements
settlements distribution. and their closest rural settlements, $\mathrm{n}$ is the number of patches. According to the above criteria, we get the evaluation index for each village by normalizing each index.

Calculating the total score of Potentiality Evaluation

The mathematical model of villages potential comprehensive evaluation can be established by selecting comprehensive analysis to treat potentiality evaluation scores of each index as quantitative indicators, thus can get their potential comprehensive evaluation scores. Calculation results, shown in Figure 4, can be obtained by formula 3.

$$
A=\sum_{i=1}^{n} a_{i} \bullet N_{i}
$$

In formula, A represents village potential comprehensive evaluation scores, and ai stands for the weight of $\mathrm{i}$-th evaluation factors, and Ni represents indicator value of $\mathrm{i}$-th evaluation factors.

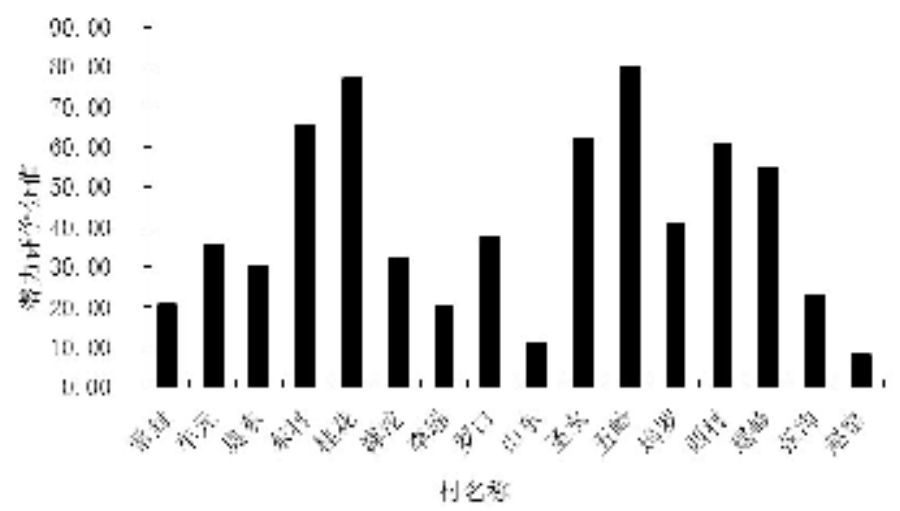

Fig.4 The statistical chart of the country-potentiality evaluation

\section{Classification gradation of evaluation results}

This study used cluster analysis to classification gradation of evaluation results. The great potential development villages should incorporate into central country preferentially, while the small ones should incorporate into demolition and incorporation country. And evaluation indexes which are at the middle level incorporate into the grassroots villages. Ultimately, we can roughly divided study area into three parts(Table 1)by running SPSS software to analyze the results.

Tab. 1 The classification of country-potentiality evaluation

\begin{tabular}{ccc}
\hline Grate & Location & Contained village \\
\hline Central Village & $\begin{array}{c}\text { Economic engine, focusing on } \\
\text { the development of the village }\end{array}$ & Xi Cun, Sheng Shui, Dong Ling, Yao Ling, Gui \\
Hrassroots Village & Economic hinterland & Wu Luo, Luo Kou, Che Yuan, Hu Tuo, Di \\
Demolition and & Area of gradually merge & Dong, Chang Feng, Li Yao, Zhang Gou \\
Incorporation Village & integration & Shan Dong, \\
\hline
\end{tabular}

In order to carry out the construction of center villages better, the main factors of affecting center villages development need to be clarified. Each village score line chart can get by gathering and 
calculating the evaluation criteria(shown in Figure 5 ).

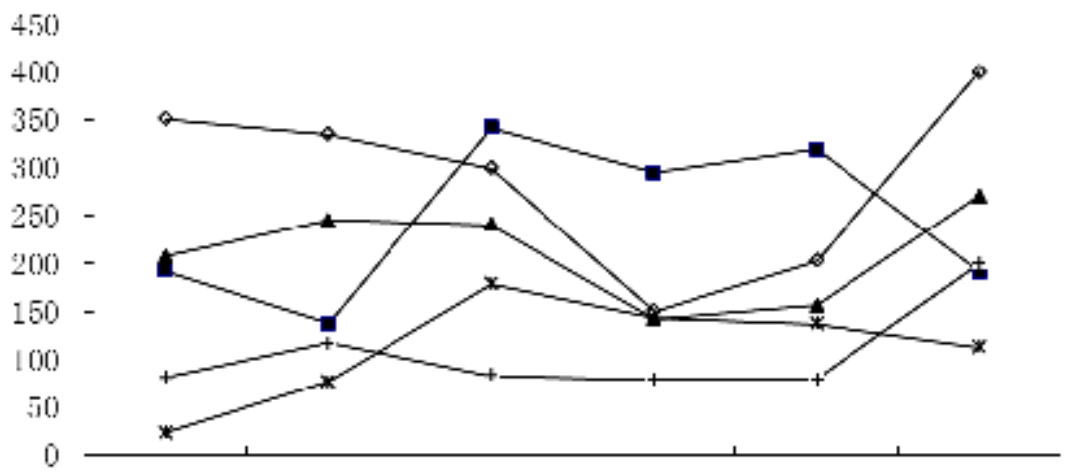

Fig.5 The statistical chart of the rule layer

\section{Contrast and verification}

This study used Voronoi Figure to verify the theory of regular hexagon. And the study put unclassified and after classifying villages to generate Voronoi Figure respectively. First operation was to contrast variation coefficient $\mathrm{Cr}$ of Voronoi figure polygon area.

When the point set distributed at randomly, the score of $\mathrm{Cr}$ is $33 \%-34 \%$; when the point set is evenly distributed, $\mathrm{Cr}$ is less than $33 \%$. Cr generated by computing the Voronoi diagram (Fig. 6) is $31.2 \%$; Cr generated Voronoi in study area (Figure 3) values 35.4\%. Thus, country layout after optimizing tends to be more evenly distributed.

If the generating sources were in accordance with the distribution of hexagonal central place theory, thus the mean number of generating Voronoi diagram polygon vertices should be 6 . The average polygon vertices' number of Voronoi diagram generated by center country is 5.4, while ones of Voronoi diagram generated by the town is 4.8. Thus the country layout after optimizing tends to be closer to the distribution of regular hexagon.

Thus, the layout are more in line with central place theory by selecting the central country to optimize the town countries, which shows that the layout scheme of the country optimization is scientific and rational.

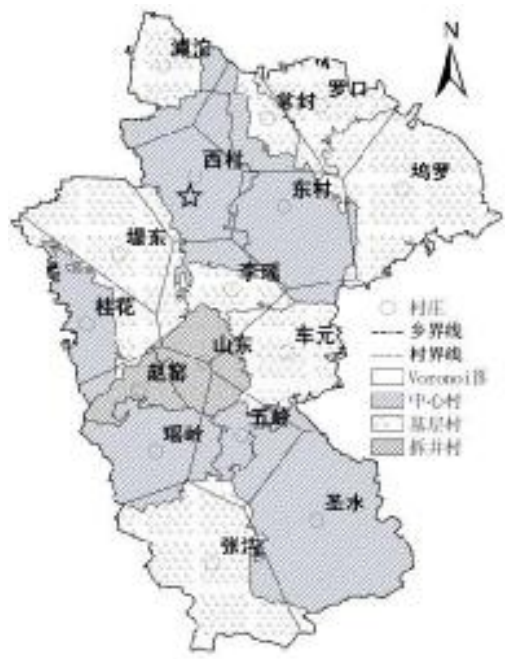

Fig.6 The allocation of Center countrysides

\section{Conclusion and discussion}

This study redefined the basic factors of affecting the central villages layout, such as geographic 
conditions, the village scale, the level of economic development, and service facilities degrees and the concentration degrees of villages. The optimization analysis of central village layout can be conducted by using GIS Spatial Analysis, Integrated Analysis of Multi-factors, Cluster Analysis, Thiessen Poiygons theory and Center Geographic theory, which can provide a scientific basis for resolving the core issue of new countryside planning - the site selection of center country. In theory it is reasonable that country layout after optimization are closer to regular hexagon. The study also need to discuss the details of Model and other social and economic factors of affecting center country layout, as well as the internal mechanism about optimizing the layout of center country.

\section{References :}

[1] LIU J Y, ZHAN J Y, DENG X Z.Spatio-temporal patterns and driving forces of urban land expansion in China during the economic reform era[J]. Royal Swedish Academy of Sciences, 2005, 34(6): 450-455.

[2] Alan T.Murray. Advances in location modeling: GIS linkages and contributions[J]. Geogr Syst, 2010(12): 335-354.

[3] Jiajun Qiao. Study on choice of village location[J]. Journal of Henan University(Natural Science), 2012, 1(42): 47-55.[In Chinese]

[4] Yucheng Ye, Jiangang $\mathrm{Xu}$, Lanjun Yu. GIS space analysis methods in town-village distribution[J]. Journal of Anhui Agricultural Sciences, 2007, 35(5): 1284-1287.[In Chinese]

[5] Yaoqi Yang. The high groundwater area of coal village migration in occupies filling balance by the theoretical model and application[D]. China University of Mining \& Technology(Beijing), 2014.[In Chinese]

[6] Qingyuan Yang, Yongzhong Tian, Chaoke Wang, etc. On the land use characteristics and the land consolidation models of rural residential area of the hilly and mountainous regions in Southwest China:a case of Chongqing[J]. Geographical Research, 2002,23(4): 472-476.[In Chinese] [7] Qingwu Yan, Zhengfu Bian. Study on Distribution Patterns of Settlements Based on GIS-SDA[J]. Geography and Geo-information Science, 2008,24(3): 57-61.[In Chinese]

[8] Qing He. Advance in Fuzzy Clustering Theory and Application[J]. Fuzzy Systems and Mathematics, 1998,12(2): 89-94. [In Chinese]

[9] Yanguang Chen. Spatial Structure of Central- Place Systems: Fractals and Scaling Laws[J].Acta Scientiarum Naturalium Universitatis Pekinensis, 2004(4): 626-634.[In Chinese] 